Article

\title{
An Iterative Approach to the Solutions of Proximal Split Feasibility Problems
}

\author{
Li-Jun Zhu ${ }^{1,2}$ and Yonghong Yao ${ }^{3, *(D)}$ \\ 1 The Key Laboratory of Intelligent Information and Data Processing of NingXia Province, \\ North Minzu University, Yinchuan 750021, China; zhulijun1995@yahoo.com \\ 2 Health Big Data Research Institute of North Minzu University, Yinchuan 750021, China \\ 3 School of Mathematical Sciences, Tianjin Polytechnic University, Tianjin 300387, China \\ * Correspondence: yaoyonghong@aliyun.com
}

Received: 10 January 2019; Accepted: 28 January 2019; Published: 3 February 2019

Abstract: The proximal split feasibility problem is investigated in Hilbert spaces. An iterative procedure is introduced for finding the solution of the proximal split feasibility problem. Strong convergence analysis of the presented algorithm is proved.

Keywords: proximal operators; Moreau-Yosida regularization; proximal split feasibility problem; iterative procedure

MSC: 47H09; 47H05; 47J25

\section{Introduction}

Recall that the split feasibility problem (SFP) seeks a point $u^{\dagger}$ such that

$$
u^{\dagger} \in \mathcal{C} \text { and } \mathcal{A} u^{\dagger} \in \mathcal{Q},
$$

where $\varnothing \neq \mathcal{C}$ and $\varnothing \neq \mathcal{Q}$ are two closed convex subsets of two real Hilbert spaces $\mathcal{H}_{1}$ and $\mathcal{H}_{2}$, respectively and $\mathcal{A}: \mathcal{H}_{1} \rightarrow \mathcal{H}_{2}$ is a bounded linear operator.

In 1994, Censor and Elfving [1] refined the above mathematical model from the medical image reconstruction and phase retrievals. This provides us a useful tool to research inverse problems arising in science and engineering. One effective method for solving SFP (1) is algorithmic iteration. In the literature, there are several effective iterative algorithms presented by some authors (see, for instance [2-28].)

In this paper, our goal is to focus a general case of proximal split feasibility problems and to investigate the convergence analysis. To begin with, we first give several related concepts.

Let $\phi: \mathcal{H}_{2} \rightarrow \mathcal{R} \cup\{+\infty\}$ be a lower semi-continuous, proper and convex function. Let $\epsilon>0$ be a constant. Recall that the Moreau [29]-Yosida [30] regularization is defined by

$$
\phi_{\epsilon}(x)=\min _{u \in \mathcal{H}_{2}}\left\{\phi(u)+\frac{1}{2 \epsilon}\|u-x\|^{2}\right\} .
$$

Consequently, we can define the proximity operator of $\phi$ by the form

$$
\operatorname{prox}_{\epsilon \phi}(x)=\arg \min _{u \in \mathcal{H}_{2}}\left\{\phi(u)+\frac{1}{2 \epsilon}\|u-x\|^{2}\right\} \text {. }
$$


The subdifferential of $\phi$ at $x^{\dagger}$ denoted by $\partial \phi\left(x^{\dagger}\right)$ is defined as follows

$$
\partial \phi\left(x^{\dagger}\right)=\left\{x^{*} \in \mathcal{H}_{2}: \phi\left(x^{\dagger}\right)+\left\langle x^{*}, x^{\ddagger}-x^{\dagger}\right\rangle \leq \phi\left(x^{\ddagger}\right), \forall x^{\ddagger} \in \mathcal{H}_{2}\right\} .
$$

It is easy to validate that $0 \in \partial \phi\left(x^{\dagger}\right) \Leftrightarrow x^{\dagger}=\operatorname{prox}_{\epsilon \phi}\left(x^{\dagger}\right)$. This means that the minimizer of $\phi$ is the fixed point of its proximity operator.

Let $\varphi: \mathcal{H}_{1} \rightarrow \mathcal{R} \cup\{+\infty\}$ be a lower semi-continuous, proper and convex function. Recall that the proximal split feasibility problem seeks a point $x^{\dagger} \in \mathcal{H}_{1}$ such that $x^{\dagger}$ solves the following minimization problem

$$
\min _{x^{\dagger} \in \mathcal{H}_{1}}\left\{\varphi\left(x^{\dagger}\right)+\phi_{\epsilon}\left(\mathcal{A} x^{\dagger}\right)\right\}
$$

In what follows, we use $\Gamma$ to denote the solution set of the problem (2).

The above problem (2) has been studied extensively in the literature, see for instance [31-35]. In order to solve problem (2), in [36], Moudafi and Thakur presented the following split proximal algorithm.

- $\quad$ Fixed an initialization $u_{0} \in \mathcal{H}_{1}$.

- $\quad$ Assume that $u_{n} \in \mathcal{H}_{1}$ has been obtained. Calculate $v\left(u_{n}\right)=\sqrt{\left\|\nabla g\left(u_{n}\right)\right\|^{2}+\left\|\nabla h\left(u_{n}\right)\right\|^{2}}$, where $g\left(u_{n}\right)=\frac{1}{2}\left\|\left(I-\operatorname{prox}_{\epsilon \phi}\right) \mathcal{A} u_{n}\right\|^{2}$ and $h\left(u_{n}\right)=\frac{1}{2}\left\|\left(I-\operatorname{prox}_{\mu_{n} \epsilon \varphi}\right) u_{n}\right\|^{2}$.

- If $v\left(u_{n}\right)=0$, then the iterative procedure stops, otherwise continue to compute the next iterate

$$
u_{n+1}=\operatorname{prox}_{\mu_{n} \epsilon \varphi}\left(u_{n}-\mu_{n} \mathcal{A}^{*}\left(I-\operatorname{prox}_{\epsilon \phi}\right) \mathcal{A} u_{n}\right), n \geq 0,
$$

where $\mu_{n}=\tau_{n} \frac{g\left(u_{n}\right)+h\left(u_{n}\right)}{v^{2}\left(u_{n}\right)}$.

Remark 1. Note that the stepsize sequence $\left\{\mu_{n}\right\}$ is implicit because of the terms $g\left(u_{n}\right)$ and $v\left(u_{n}\right)$. This indicates that the computation of $u_{n+1}$ is complicated.

To overcome this difficulty, Shehu and Iyiola [37] suggested the following explicit algorithm to solve problem (2).

1. Fixed $u \in \mathcal{H}_{1}$ and $u_{1} \in \mathcal{H}_{1}$.

2. Set $n=1$ and calculate

$$
\left\{\begin{array}{l}
y_{n}=\zeta_{n} u+\left(1-\zeta_{n}\right) u_{n}, \\
v\left(y_{n}\right)=\left\|\mathcal{A}^{*}\left(I-\operatorname{prox}_{\epsilon \phi}\right) \mathcal{A} y_{n}+\left(I-\operatorname{prox}_{\epsilon \varphi}\right) y_{n}\right\|, \\
z_{n}=y_{n}-\tau_{n} \frac{h\left(y_{n}\right)+l\left(y_{n}\right)}{v^{2}\left(y_{n}\right)}\left(\mathcal{A}^{*}\left(I-\operatorname{prox}_{\epsilon \phi}\right) \mathcal{A} y_{n}+\left(I-\operatorname{prox}_{\epsilon \varphi}\right) y_{n}\right), \\
u_{n+1}=\left(1-\vartheta_{n}\right) y_{n}+\vartheta_{n} z_{n} .
\end{array}\right.
$$

3. If $\mathcal{A}^{*}\left(I-\operatorname{prox}_{\epsilon \phi}\right) \mathcal{A} y_{n}=0=\left(I-\operatorname{prox}_{\epsilon \varphi}\right) y_{n}$ and $u_{n+1}=u_{n}$, then the iterative process stops, otherwise continue to the next step.

4. Set $n \leftarrow n+1$ and repeat steps $2-3$.

Remark 2. In Step 3, we note that $\mathcal{A}^{*}\left(I-\operatorname{prox}_{\epsilon \phi}\right) \mathcal{A} y_{n}=0=\left(I-\operatorname{prox}_{\epsilon \varphi}\right) y_{n}$ implies $v\left(y_{n}\right)=0$. In this case, the iterates $z_{n}$ and $u_{n+1}$ have no meanings.

In the present paper, our goal is to mend the above gap and to suggest a modified proximal split feasibility algorithm for solving the proximal split feasibility problem (2). We prove that the presented sequence converges strongly to a solution of the proximal split feasibility problem (2). 


\section{Preliminaries}

Let $\mathcal{H}$ be a real Hilbert space. Use $\langle\cdot, \cdot\rangle$ and $\|\cdot\|$ to denote its inner product and norm, respectively. Let $\mathcal{C}$ be a nonempty closed convex subset of $\mathcal{H}$. Recall that a mapping $S: \mathcal{C} \rightarrow \mathcal{C}$ is said to be firmly nonexpansive [38] if

$$
\|S u-S v\|^{2} \leq\langle S u-S v, u-v\rangle
$$

for all $u, v \in \mathcal{C}$.

Note that the proximal operators $I-\operatorname{prox}_{\epsilon \varphi}$ and $I-\operatorname{prox}_{\epsilon \phi}$ are firmly nonexpansive, namely,

$$
\left\|\left(I-\operatorname{prox}_{\epsilon \varphi}\right) u-\left(I-\operatorname{prox}_{\epsilon \varphi}\right) v\right\|^{2} \leq\left\langle\left(I-\operatorname{prox}_{\epsilon \varphi}\right) u-\left(I-\operatorname{prox}_{\epsilon \varphi}\right) v, u-v\right\rangle
$$

for all $u, v \in \mathcal{H}_{1}$ and

$$
\left\|\left(I-\operatorname{prox}_{\epsilon \phi}\right) u-\left(I-\operatorname{prox}_{\epsilon \phi}\right) v\right\|^{2} \leq\left\langle\left(I-\operatorname{prox}_{\epsilon \phi}\right) u-\left(I-\operatorname{prox}_{\epsilon \phi}\right) v, u-v\right\rangle
$$

for all $u, v \in \mathcal{H}_{2}$.

For $\forall u \in \mathcal{H}$, there exists a unique point in $\mathcal{C}$, denoted by $\operatorname{proj}_{\mathcal{C}}(u)$, such that

$$
\left\|u-\operatorname{proj}_{\mathcal{C}}(u)\right\| \leq\left\|u-u^{\dagger}\right\|
$$

for all $u^{\dagger} \in \mathcal{C}$.

It is known that $\operatorname{proj}_{\mathcal{C}}$ is firmly-nonexpansive and has the following characteristic [39]

$$
\left\langle u-\operatorname{proj}_{\mathcal{C}}(u), u^{\dagger}-\operatorname{proj}_{\mathcal{C}}(u)\right\rangle \leq 0
$$

for all $u \in \mathcal{H}$ and $u^{\dagger} \in \mathcal{C}$.

An operator $F$ is called strongly positive if there exists a constant $\delta>0$ such that $\langle F u, u\rangle \geq \delta\|u\|^{2}$ for all $u \in \mathcal{H}$.

The following expressions will be used in the sequel.

- $u_{n} \rightarrow u$ denotes the weak convergence of $\left\{u_{n}\right\}$ to $u$;

- $u_{n} \rightarrow u$ denotes the strong convergence of $\left\{u_{n}\right\}$ to $u$;

- $\operatorname{Fix}(S)$ means the set of fixed points of $S$.

Lemma 1. [40] In a real Hilbert space $\mathcal{H}$, the following identity holds

$$
\left\|\lambda x^{\dagger}+(1-\lambda) \tilde{x}\right\|^{2}=\lambda\left\|x^{\dagger}\right\|^{2}+(1-\lambda)\|\tilde{x}\|^{2}-\lambda(1-\lambda)\left\|x^{\dagger}-\tilde{x}\right\|^{2},
$$

for all $\lambda \in[0,1], \forall x^{\dagger}, \tilde{x} \in \mathcal{H}$.

Lemma 2. [41] Suppose that three sequences $\left\{u_{n}\right\},\left\{v_{n}\right\}$ and $\left\{\theta_{n}\right\}$ satisfy the following conditions

(i) $u_{n} \geq 0$ for all $n \geq 0$;

(ii) there exists a constant $M$ such that $v_{n} \leq M$ for all $n \geq 0$;

(iii) $\theta_{n} \in[0,1]$ and $\sum_{n=0}^{\infty} \theta_{n}=\infty$;

(iv) $u_{n+1} \leq\left(1-\theta_{n}\right) u_{n}+\theta_{n} v_{n}$ for all $n \geq 0$.

Then, we have $\lim \sup _{n \rightarrow \infty} u_{n} \leq \limsup _{n \rightarrow \infty} v_{n}$.

Lemma 3. [42] Suppose that $\mathcal{H}$ is a real Hilbert space and $\mathcal{C} \subset \mathcal{H}$ is a nonempty closed convex set. If $T$ is a nonexpansive self-mapping of $\mathcal{C}$, then the operator $I-T$ is demi-closed at 0 , i.e., $x_{n} \rightarrow x \in \mathcal{C}$ and $x_{n}-T x_{n} \rightarrow 0$ imply $x=T x$. 
Lemma 4. [43] Assume that three sequences $\left\{\rho_{n}\right\},\left\{\eta_{n}\right\}$ and $\left\{\zeta_{n}\right\}$ satisfy the following assumptions

(i) $\rho_{n} \geq 0$ for all $n \geq 0$;

(ii) $\left\{\zeta_{n}\right\}_{n \in \mathbb{N}} \subset[0,1]$ and $\sum_{n=1}^{\infty} \zeta_{n}=\infty$;

(iii) $\lim \sup _{n \rightarrow \infty} \eta_{n} \leq 0$;

(iv) $\rho_{n+1} \leq\left(1-\zeta_{n}\right) \rho_{n}+\zeta_{n} \eta_{n}$ for all $n \geq 0$.

Then $\lim _{n \rightarrow \infty} \rho_{n}=0$.

\section{Main Results}

Suppose that

(i) $\mathcal{H}_{1}$ and $\mathcal{H}_{2}$ are two real Hilbert spaces and $\varnothing \neq C \subset \mathcal{H}_{1}$ and $\varnothing \neq Q \subset H_{2}$ are two closed convex sets;

(ii) $\mathcal{A}: \mathcal{H}_{1} \rightarrow \mathcal{H}_{2}$ is a bounded linear operator, $\varphi: \mathcal{H}_{1} \rightarrow \mathcal{R} \cup\{+\infty\}$ and $\phi: \mathcal{H}_{2} \rightarrow \mathcal{R} \cup\{+\infty\}$ are two proper, convex and lower semi-continuous functions.

In what follows, assume $\Gamma \neq \varnothing$. The following lemma plays a key role for constructing our algorithm and proving our main result.

Lemma 5. [34] $z^{\dagger} \in \Gamma$ iff $\mathcal{A}^{*}\left(I-\operatorname{prox}_{\epsilon \phi}\right) \mathcal{A} z^{\dagger}+\left(I-\operatorname{prox}_{\epsilon \varphi}\right) z^{\dagger}=0$.

Next, we suggest the following algorithm by applying Lemma 5 .

Let $f: \mathcal{H}_{1} \rightarrow \mathcal{H}_{1}$ be a $\mu$-contraction. Let $F: \mathcal{H}_{1} \rightarrow \mathcal{H}_{1}$ be a strongly positive linear bounded operator with coefficient $\delta>0$. Let $\left\{\zeta_{n}\right\} \subset(0,1),\left\{\vartheta_{n}\right\} \subset(0,1)$ and $\left\{\tau_{n}\right\} \subset(0,+\infty)$ be three real number sequences. Let $\gamma$ be a constant such that $\delta / \mu>\gamma>0$.

1. Given fixed point $x_{0} \in \mathcal{H}_{1}$. Set $n=0$.

2. Calculate $y_{n}$ and $v\left(y_{n}\right)$ via the iterative procedures

$$
y_{n}=\zeta_{n} \gamma f\left(x_{n}\right)+\left(I-\zeta_{n} F\right) x_{n}
$$

and

$$
v\left(y_{n}\right)=\mathcal{A}^{*}\left(I-\operatorname{prox}_{\epsilon \phi}\right) \mathcal{A} y_{n}+\left(I-\operatorname{prox}_{\epsilon \varphi}\right) y_{n} .
$$

3. If $v\left(y_{n}\right)=0$, then the iterative process stops (in this case, $y_{n}$ is a solution of (2) by Lemma 5), otherwise continuous to the next step.

4. Compute

$$
x_{n+1}=\left(1-\vartheta_{n}\right) y_{n}+\vartheta_{n} z_{n}
$$

where

$$
z_{n}=y_{n}-\tau_{n} \frac{g\left(y_{n}\right)+h\left(y_{n}\right)}{\left\|v\left(y_{n}\right)\right\|^{2}} v\left(y_{n}\right)
$$

in which $g\left(y_{n}\right)=\frac{1}{2}\left\|\left(I-\operatorname{prox}_{\epsilon \phi}\right) \mathcal{A} y_{n}\right\|^{2}$ and $h\left(y_{n}\right)=\frac{1}{2}\left\|\left(I-\operatorname{prox}_{\epsilon \varphi}\right) y_{n}\right\|^{2}$.

5. Set $n \leftarrow n+1$ and repeat steps $2-4$.

Assume that the above iterates (5)-(8) do not terminate, that is, the sequence $\left\{x_{n}\right\}$ generated by (7) is very large. In this case, we demonstrate the convergence analysis of the sequence $\left\{x_{n}\right\}$.

Theorem 1. Suppose that the control parameters $\left\{\zeta_{n}\right\},\left\{\vartheta_{n}\right\}$ and $\left\{\tau_{n}\right\}$ satisfy the following restrictions 
(C1): $\lim _{n \rightarrow \infty} \zeta_{n}=0$ and $\sum_{n=0}^{\infty} \zeta_{n}=\infty$;

(C2): $0<\liminf _{n \rightarrow \infty} \vartheta_{n} \leq \limsup _{n \rightarrow \infty} \vartheta_{n}<1$;

(C3): $\liminf _{n \rightarrow \infty} \tau_{n}\left(4-\tau_{n}\right)>0$.

Then sequence $\left\{x_{n}\right\}$ generated by (7) strongly converges to $z$, where $z=\operatorname{proj}_{\Gamma}(I-F+\gamma f) z$.

Proof. Firstly, it is easy to check that operator $\operatorname{proj}_{\Gamma}(I-F+\gamma f)$ is a contraction under the restriction $\delta / \mu>\gamma>0$. Denote its unique fixed point by $z$, that is, $z=\operatorname{proj}_{\Gamma}(I-F+\gamma f) z$. Next, we show the boundedness of the sequence $\left\{x_{n}\right\}$. In terms of the nonexpansivity of the operators $I-\operatorname{prox}_{\epsilon \phi}$ and $I-\operatorname{prox}_{\epsilon \varphi}$, from (3) and (4), we have

$$
2 h\left(y_{n}\right)=\left\|\left(I-\operatorname{prox}_{\epsilon \varphi}\right) y_{n}\right\|^{2} \leq\left\langle\left(I-\operatorname{prox}_{\epsilon \varphi}\right) y_{n}, y_{n}-z\right\rangle
$$

and

$$
2 g\left(y_{n}\right)=\left\|\left(I-\operatorname{prox}_{\epsilon \phi}\right) \mathcal{A} y_{n}\right\|^{2} \leq\left\langle\left(I-\operatorname{prox}_{\epsilon \phi}\right) \mathcal{A} y_{n}, \mathcal{A} y_{n}-\mathcal{A} z\right\rangle .
$$

By (6), (9) and (10), we obtain

$$
\begin{aligned}
\left\langle v\left(y_{n}\right), y_{n}-z\right\rangle & =\left\langle\mathcal{A}^{*}\left(I-\operatorname{prox}_{\epsilon \phi}\right) \mathcal{A} y_{n}+\left(I-\operatorname{prox}_{\epsilon \varphi}\right) y_{n}, y_{n}-z\right\rangle \\
& =\left\langle\left(I-\operatorname{prox}_{\epsilon \phi}\right) \mathcal{A} y_{n}, \mathcal{A} y_{n}-\mathcal{A} z\right\rangle+\left\langle\left(I-\operatorname{prox}_{\epsilon \varphi}\right) y_{n}, y_{n}-z\right\rangle \\
& \geq 2 g\left(y_{n}\right)+2 h\left(y_{n}\right) .
\end{aligned}
$$

This together with (8) implies that

$$
\begin{aligned}
\left\|z_{n}-z\right\|^{2} & =\left\|y_{n}-\tau_{n} \frac{g\left(y_{n}\right)+h\left(y_{n}\right)}{\left\|v\left(y_{n}\right)\right\|^{2}} v\left(y_{n}\right)-z\right\| \\
& =\left\|y_{n}-z\right\|^{2}-2 \tau_{n} \frac{g\left(y_{n}\right)+h\left(y_{n}\right)}{\left\|v\left(y_{n}\right)\right\|^{2}}\left\langle v\left(y_{n}\right), y_{n}-z\right\rangle+\tau_{n}^{2} \frac{\left(g\left(y_{n}\right)+h\left(y_{n}\right)\right)^{2}}{\left\|v\left(y_{n}\right)\right\|^{2}} \\
& \leq\left\|y_{n}-z\right\|^{2}-\tau_{n}\left(4-\tau_{n}\right) \frac{\left(g\left(y_{n}\right)+h\left(y_{n}\right)\right)^{2}}{\left\|v\left(y_{n}\right)\right\|^{2}} .
\end{aligned}
$$

By condition (C3), without loss of generality, we assume $0<a<\tau_{n}<b<4$ for all $n \geq 0$. In the light of (7) and (12), we have

$$
\begin{aligned}
\left\|x_{n+1}-z\right\| & \leq\left(1-\vartheta_{n}\right)\left\|y_{n}-z\right\|+\vartheta_{n}\left\|z_{n}-z\right\| \\
& \leq\left\|y_{n}-z\right\| \\
& =\left\|\zeta_{n} \gamma\left(f\left(x_{n}\right)-f(z)\right)+\zeta_{n}(\gamma f(z)-F(z))+\left(I-\zeta_{n} F\right)\left(x_{n}-z\right)\right\| \\
& \leq \zeta_{n} \gamma \mu\left\|x_{n}-z\right\|+\zeta_{n}\|\gamma f(z)-F(z)\|+\left(1-\delta \zeta_{n}\right)\left\|x_{n}-z\right\| \\
& =\left[1-(\delta-\gamma \mu) \zeta_{n}\right]\left\|x_{n}-z\right\|+\zeta_{n}\|\gamma f(z)-F(z)\| \\
& \leq \max \left\{\left\|x_{n}-z\right\|, \frac{\|\gamma f(z)-F(z)\|}{\delta-\gamma \mu}\right\} \\
& \leq \cdots \\
& \leq \max \left\{\left\|x_{0}-z\right\|, \frac{\|\gamma f(z)-F(z)\|}{\delta-\gamma \mu}\right\} .
\end{aligned}
$$

Hence, the sequence $\left\{x_{n}\right\}$ is bounded. Consequently, we can check easily that the sequences $\left\{y_{n}\right\}$ and $\left\{z_{n}\right\}$ are bounded. 
By virtue of (5), we have

$$
\begin{aligned}
\left\|y_{n}-z\right\|^{2}= & \left\|\zeta_{n}\left(\gamma f\left(x_{n}\right)-F(z)\right)+\left(I-\zeta_{n} F\right)\left(x_{n}-z\right)\right\|^{2} \\
\leq & \left\|I-\zeta_{n} F\right\|^{2}\left\|x_{n}-z\right\|^{2}+\zeta_{n}^{2}\left\|\gamma f\left(x_{n}\right)-F(z)\right\|^{2}+2 \zeta_{n}\left\langle\gamma f\left(x_{n}\right)-F(z),\left(I-\zeta_{n} F\right)\left(x_{n}-z\right)\right\rangle \\
\leq & \left(1-\delta \zeta_{n}\right)^{2}\left\|x_{n}-z\right\|^{2}+\zeta_{n}^{2}\left\|\gamma f\left(x_{n}\right)-F(z)\right\|^{2}+2 \gamma \zeta_{n}\left\langle f\left(x_{n}\right)-f(z),\left(I-\zeta_{n} F\right)\left(x_{n}-z\right)\right\rangle \\
& +2 \zeta_{n}\left\langle\gamma f(z)-F(z), x_{n}-z\right\rangle-2 \zeta_{n}^{2}\left\langle\gamma f(z)-F(z), F\left(x_{n}\right)-F(z)\right\rangle \\
\leq & \left(1-\delta \zeta_{n}\right)^{2}\left\|x_{n}-z\right\|^{2}+\zeta_{n}^{2}\left\|\gamma f\left(x_{n}\right)-F(z)\right\|^{2}+2 \gamma \mu\left(1-\delta \zeta_{n}\right) \zeta_{n}\left\|x_{n}-z\right\|^{2} \\
& +2 \delta \zeta_{n}^{2}\|\gamma f(z)-F(z)\|\left\|x_{n}-z\right\|+2 \zeta_{n}\left\langle\gamma f(z)-F(z), x_{n}-z\right\rangle \\
\leq & {\left[1-2(\delta-\gamma \mu) \zeta_{n}\right]\left\|x_{n}-z\right\|^{2}+2 \zeta_{n}\left\langle\gamma f(z)-F(z), x_{n}-z\right\rangle+\zeta_{n}^{2} M_{1}, }
\end{aligned}
$$

where $M_{1} \geq \sup _{n>0}\left\{\left\|\gamma f\left(x_{n}\right)-F(z)\right\|, 2 \delta\left\|\gamma f\left(x_{n}\right)-F(z)\right\|\left\|x_{n}-z\right\|, \delta^{2}\left\|x_{n}-z\right\|^{2}\right\}$.

On the basis of (7) and Lemma 1, we get

$$
\begin{aligned}
\left\|x_{n+1}-z\right\|^{2} & =\left\|\left(1-\vartheta_{n}\right)\left(y_{n}-z\right)+\vartheta_{n}\left(z_{n}-z\right)\right\|^{2} \\
& =\left(1-\vartheta_{n}\right)\left\|y_{n}-z\right\|^{2}+\vartheta_{n}\left\|z_{n}-z\right\|^{2}-\left(1-\vartheta_{n}\right) \vartheta_{n}\left\|y_{n}-z_{n}\right\|^{2} .
\end{aligned}
$$

From (12) and (15), we deduce

$$
\left\|x_{n+1}-z\right\|^{2} \leq\left\|y_{n}-z\right\|^{2}-\left(1-\vartheta_{n}\right) \vartheta_{n}\left\|y_{n}-z_{n}\right\|^{2} .
$$

By (7), we note that

$$
y_{n}-z_{n}=\frac{1}{\vartheta_{n}}\left(y_{n}-x_{n+1}\right) .
$$

Thus, combining (14), (16) with (25), we get

$$
\begin{aligned}
\left\|x_{n+1}-z\right\|^{2} \leq & \left\|y_{n}-z\right\|^{2}-\frac{1-\vartheta_{n}}{\vartheta_{n}}\left\|x_{n+1}-y_{n}\right\|^{2} \\
\leq & {\left[1-2(\delta-\gamma \mu) \zeta_{n}\right]\left\|x_{n}-z\right\|^{2}+2 \zeta_{n}\left\langle\gamma f(z)-F(z), x_{n}-z\right\rangle } \\
& +\zeta_{n}^{2} M_{1}-\frac{1-\vartheta_{n}}{\vartheta_{n}}\left\|x_{n+1}-y_{n}\right\|^{2} \\
= & {\left[1-2(\delta-\gamma \mu) \zeta_{n}\right]\left\|x_{n}-z\right\|^{2}+\zeta_{n} \sigma_{n}, }
\end{aligned}
$$

where

$$
\sigma_{n}=2\left\langle\gamma f(z)-F(z), x_{n}-z\right\rangle+M_{1} \zeta_{n}-\frac{1-\vartheta_{n}}{\zeta_{n} \vartheta_{n}}\left\|x_{n+1}-y_{n}\right\|^{2} .
$$

According to the boundedness of the sequence $\left\{x_{n}\right\}$, from (27), we obtain $\sigma_{n} \leq M_{2}(\forall n \geq 0)$ for some $M_{2}$. Applying Lemma 2 to (26), we get $0 \leq 2(\delta-\gamma \mu) \limsup _{n \rightarrow \infty}\left\|x_{n}-z\right\|^{2} \leq \limsup _{n \rightarrow \infty} \sigma_{n} \leq$ $M_{2}$. Therefore, $\limsup _{n \rightarrow \infty} \sigma_{n}$ exists and there exists a subsequence $\left\{x_{n_{i}}\right\}$ of $\left\{x_{n}\right\}$ such that $x_{n_{i}} \rightarrow \tilde{x}$ and

$$
\begin{aligned}
\limsup _{n \rightarrow \infty} \sigma_{n} & =\limsup _{n \rightarrow \infty}\left(2\left\langle\gamma f(z)-F(z), x_{n}-z\right\rangle+M_{1} \zeta_{n}-\frac{1-\vartheta_{n}}{\zeta_{n} \vartheta_{n}}\left\|x_{n+1}-y_{n}\right\|^{2}\right) \\
& =\lim _{i \rightarrow \infty}\left(2\langle\gamma f(z)-F(z), \tilde{x}-z\rangle-\frac{1-\vartheta_{n_{i}}}{\zeta_{n_{i}} \vartheta_{n_{i}}}\left\|x_{n_{i}+1}-y_{n_{i}}\right\|^{2}\right) .
\end{aligned}
$$

This indicates that $\lim _{i \rightarrow \infty} \frac{1-\vartheta_{n_{i}}}{\zeta_{n_{i}} \vartheta_{n_{i}}}\left\|x_{n_{i}+1}-y_{n_{i}}\right\|^{2}$ exists and by conditions (C1) and (C2), we deduce

$$
\lim _{i \rightarrow \infty}\left\|x_{n_{i}+1}-y_{n_{i}}\right\|=0
$$


This together with (25) implies that

$$
\lim _{i \rightarrow \infty}\left\|y_{n_{i}}-z_{n_{i}}\right\|=0
$$

Combining (5) with (21), we obtain

$$
\lim _{i \rightarrow \infty}\left\|x_{n_{i}+1}-x_{n_{i}}\right\|=\lim _{i \rightarrow \infty}\left\|y_{n_{i}}-x_{n_{i}}\right\|=0 .
$$

By (12), we have

$$
\begin{aligned}
0 \leq \tau_{n_{i}}\left(4-\tau_{n_{i}}\right) \frac{\left(g\left(y_{n_{i}}\right)+h\left(y_{n_{i}}\right)\right)^{2}}{\left\|v\left(y_{n_{i}}\right)\right\|^{2}} & \leq\left\|y_{n_{i}}-z\right\|^{2}-\left\|z_{n_{i}}-z\right\|^{2} \\
& \leq\left\|y_{n_{i}}-z_{n_{i}}\right\|\left(\left\|y_{n_{i}}-z\right\|+\left\|z_{n_{i}}-z\right\|\right) \rightarrow 0(\text { as } i \rightarrow \infty) .
\end{aligned}
$$

It follows that

$$
\lim _{i \rightarrow \infty} \frac{g\left(y_{n_{i}}\right)+h\left(y_{n_{i}}\right)}{\left\|v\left(y_{n_{i}}\right)\right\|}=0
$$

Noting that $v\left(y_{n_{i}}\right)$ is bounded, from (23), we deduce $\lim _{i \rightarrow \infty}\left(g\left(y_{n_{i}}\right)+h\left(y_{n_{i}}\right)\right)=0$. Thus, $\lim _{i \rightarrow \infty} g\left(y_{n_{i}}\right)=\lim _{i \rightarrow \infty} h\left(y_{n_{i}}\right)=0$. That is,

$$
\lim _{i \rightarrow \infty}\left\|\left(I-\operatorname{prox}_{\epsilon \varphi}\right) y_{n_{i}}\right\|=\lim _{i \rightarrow \infty}\left\|\left(I-\operatorname{prox}_{\epsilon \phi}\right) \mathcal{A} y_{n_{i}}\right\|=0 .
$$

This together with Lemma 3 implies that $\tilde{x} \in$ Fix $\left(\operatorname{prox}_{\epsilon \varphi}\right)$ and $A \tilde{x} \in$ Fix $\left(\operatorname{prox}_{\epsilon \phi}\right)$. Hence $\tilde{x} \in \Gamma$. Therefore,

$$
\limsup _{n \rightarrow \infty}\left\langle\gamma f(z)-F(z), x_{n}-z\right\rangle=\langle\gamma f(z)-F(z), \tilde{x}-z\rangle \leq 0 .
$$

By (26), we have

$$
\left\|x_{n+1}-z\right\|^{2} \leq\left[1-2(\delta-\gamma \mu) \zeta_{n}\right]\left\|x_{n}-z\right\|^{2}+2 \zeta_{n}\left\langle\gamma f(z)-F(z), x_{n}-z\right\rangle+\zeta_{n}^{2} M_{1} .
$$

According to Lemma 4 and (24), we deduce that $x_{n} \rightarrow z$. This completes the proof.

1. Given fixed point $x_{0} \in \mathcal{H}_{1}$. Set $n=0$.

2. Calculate $y_{n}$ and $v\left(y_{n}\right)$ via the iterative procedures

$$
y_{n}=\left(1-\zeta_{n}\right) x_{n}
$$

and

$$
v\left(y_{n}\right)=\mathcal{A}^{*}\left(I-\operatorname{prox}_{\epsilon \phi}\right) \mathcal{A} y_{n}+\left(I-\operatorname{prox}_{\epsilon \varphi}\right) y_{n} .
$$

3. If $v\left(y_{n}\right)=0$, then the iterative process stops (in this case, $y_{n} \in \Gamma$ by Lemma 5), otherwise continuous to the next step.

4. Compute

$$
x_{n+1}=\left(1-\vartheta_{n}\right) y_{n}+\vartheta_{n} z_{n}
$$

where

$$
z_{n}=y_{n}-\tau_{n} \frac{g\left(y_{n}\right)+h\left(y_{n}\right)}{\left\|v\left(y_{n}\right)\right\|^{2}} v\left(y_{n}\right)
$$

in which $g\left(y_{n}\right)=\frac{1}{2}\left\|\left(I-\operatorname{prox}_{\epsilon \phi}\right) \mathcal{A} y_{n}\right\|^{2}$ and $h\left(y_{n}\right)=\frac{1}{2}\left\|\left(I-\operatorname{prox}_{\epsilon \varphi}\right) y_{n}\right\|^{2}$. 
5. Set $n \leftarrow n+1$ and repeat steps $2-4$.

Assume that the above iterates (25)-(28) do not terminate, that is, the sequence $\left\{x_{n}\right\}$ generated by (27) is very large.

Corollary 1. Suppose that the control parameters $\left\{\zeta_{n}\right\},\left\{\vartheta_{n}\right\}$ and $\left\{\tau_{n}\right\}$ satisfy the restrictions (C1)-(C3). Then sequence $\left\{x_{n}\right\}$ generated by (27) strongly converges to $z=\operatorname{proj}_{\Gamma}(0)$, the minimum norm element in $\Gamma$.

Author Contributions: All the authors have contributed equally to this paper. All the authors have read and approved the final manuscript.

Funding: This research was partially supported by the grants NSFC61362033 and NZ17015 and the Major Projection of North Minzu University (ZDZX201805).

Conflicts of Interest: The authors declare no conflict of interest.

\section{References}

1. Censor, Y.; Elfving, T. A multiprojection algorithm using Bregman projections in a product space. Numer. Algorithms 1994, 8, 221-239. [CrossRef]

2. Cho, S.-Y.; Qin, X.; Yao, J.-C.; Yao, Y.-H. Viscosity approximation splitting methods for monotone and nonexpansive operators in Hilbert spaces. J. Nonlinear Convex Anal. 2018, 19 251-264.

3. Byrne, C. Iterative oblique projection onto convex subsets and the split feasibility problem. Inverse Probl. 2002, 18 441-453. [CrossRef]

4. Xu, J.; Chi, E.-C.; Yang, M.; Lange, K. A majorization-minimization algorithm for split feasibility problems. Comput. Optim. Appl. 2018, 71, 795-828. [CrossRef]

5. Wang, F; $\mathrm{Xu}, \mathrm{H} .-\mathrm{K}$. Approximating curve and strong convergence of the $\mathrm{CQ}$ algorithm for the split feasibility problem. J. Inequal. Appl. 2010, 2010, 102085. [CrossRef]

6. Yao, Y.; Postolache, M.; Yao, J.-C. An iterative algorithm for solving the generalized variational inequalities and fixed points problems. Mathematics 2019, 7, 61. [CrossRef]

7. Yao, Y.; Postolache, M.; Liou, Y.-C. Strong convergence of a self-adaptive method for the split feasibility problem. Fixed Point Theory Appl. 2013, 2013, 201. [CrossRef]

8. Yao, Y.; Liou, Y.-C.; Postolache, M. Self-adaptive algorithms for the split problem of the demicontractive operators. Optimization 2018, 67, 1309-1319. [CrossRef]

9. Yao, Y.; Yao, J.-C.; Liou, Y.-C.; Postolache, M. Iterative algorithms for split common fixed points of demicontractive operators without priori knowledge of operator norms. Carpathian J. Math. 2018, 34, 459-466.

10. Hieu, D.-V. Parallel extragradient-proximal methods for split equilibrium problems. Math. Model. Anal. 2016, 21, 478-501. [CrossRef]

11. Yao, Y.; Wu, J.; Liou, Y.-C. Regularized methods for the split feasibility problem. Abstr. Appl. Anal. 2012, 2012, 140679. [CrossRef]

12. Yao, Y.-H.; Liou, Y.-C.; Yao, J.-C. Split common fixed point problem for two quasi-pseudocontractive operators and its algorithm construction. Fixed Point Theory Appl. 2015, 2015, 127. [CrossRef]

13. Petrot, N.; Suwannaprapa, M.; Dadashi, V. Convergence theorems for split feasibility problems on a finite sum of monotone operators and a family of nonexpansive mappings. J. Inequal. Appl. 2018, 2018, 205. [CrossRef]

14. Moudafi, A.; Gibali, A. $l_{1}-l_{2}$ regularization of split feasibility problems. Numer. Algorithms 2018, 78, 739-757. [CrossRef]

15. Gibali, A.; Liu, L.W.; Tang, Y.-C. Note on the modified relaxation CQ algorithm for the split feasibility problem. Optim. Lett. 2018, 12, 817-830. [CrossRef]

16. Wang, F. Polyak's gradient method for split feasibility problem constrained by level sets. Numer. Algorithms 2018, 77, 925-938. [CrossRef]

17. He, S.; Tian, H.; Xu, H.-K. The selective projection method for convex feasibility and split feasibility problems. J. Nonlinear Convex Anal. 2018, 19, 1199-1215.

18. Yao, Y.; Liou, Y.-C.; Yao, J.-C. Iterative algorithms for the split variational inequality and fixed point problems under nonlinear transformations. J. Nonlinear Sci. Appl. 2017, 10 843-854. [CrossRef] 
19. Duong, V.-T.; Dang, V.-H. An inertial method for solving split common fixed point problems. J. Fixed Point Theory Appl. 2017, 19, 3029-3051.

20. Buong, N. Iterative algorithms for the multiple-sets split feasibility problem in Hilbert spaces. Numer. Algorithms 2017, 76, 783-798. [CrossRef]

21. Dadashi, V. Shrinking projection algorithms for the split common null point problem. Bull. Aust. Math. Soc. 2017, 96, 299-306. [CrossRef]

22. Takahashi, W. The split common null point problem for generalized resolvents in two banach spaces. Numer. Algorithms 2017, 75, 1065-1078. [CrossRef]

23. Yao, Y.; Agarwal, R.-P.; Postolache, M.; Liou, Y.-C. Algorithms with strong convergence for the split common solution of the feasibility problem and fixed point problem. Fixed Point Theory Appl. 2014, 2014, 183. [CrossRef]

24. Qu, B.; Wang, C.; Xiu, N. Analysis on Newton projection method for the split feasibility problem. Computat. Optim. Appl. 2017, 67, 175-199. [CrossRef]

25. Dong, Q.-L.; Tang, Y.-C.; Cho, Y.-J.; Rassias, T.-M. Optimal choice of the step length of the projection and contraction methods for solving the split feasibility problem. J. Glob. Optim. 2018, 71, 341-360. [CrossRef]

26. Yao, Y.; Postolache, M.; Zhu, Z. Gradient methods with selection technique for the multiple-sets split feasibility problem. Optimization 2019, in press.

27. Dadashi, V.; Postolache, M. Forward-backward splitting algorithm for fixed point problems and zeros of the sum of monotone operators. Arab. J. Math. 2019. [CrossRef]

28. Yao, Y.; Leng, L.; Postolache, M.; Zheng, X. Mann-type iteration method for solving the split common fixed point problem. J. Nonlinear Convex Anal. 2017, 18, 875-882.

29. Moreau, J.-J. Proximite et dualite dans un espace hilbertien. Bull. Soc. Math. 1965, 93, 273-299. [CrossRef]

30. Yosida, K. Functional Analysis; Springer: Berlin, Germany, 1964.

31. Shehu, Y.; Cai, G.; Iyiola, O.-S. Iterative approximation of solutions for proximal split feasibility problems. Fixed Point Theory Appl. 2015, 2015, 123. [CrossRef]

32. Abbas, M.; AlShahrani, M.; Ansari, Q.-H.; Iyiola, O.-S.; Shehu, Y. Iterative methods for solving proximal split minimization problems. Numer. Algorithms 2018, 78, 193-215. [CrossRef]

33. Witthayarat, U.; Cho, Y.-J.; Cholamjiak, P. On solving proximal split feasibility problems and applications. Ann. Funct. Anal. 2018, 9, 111-122. [CrossRef]

34. Yao, Y.; Qin, X.; Yao, J.-C. Constructive approximation of solutions to proximal split feasibility problems. J. Nonlinear Convex Anal. 2019, in press.

35. Yao, Y.; Postolache, M.; Qin, X.; Yao, J.-C. Iterative algorithms for the proximal split feasibility problem. UPB Sci. Ser. A Appl. Math. Phys. 2018, 80,37-44.

36. Moudafi, A.; Thakur, B.-S. Solving proximal split feasibility problems without prior knowledge of operator norms. Optim. Lett. 2014, 8, 2099-2110. [CrossRef]

37. Shehu Y.; Iyiola, O.-S. Strong convergence result for proximal split feasibility problem in Hilbert spaces. Optimization 2017, 66, 2275-2290. [CrossRef]

38. Yao, Y.-H.; Qin, X.; Yao, J.-C. Projection methods for firmly type nonexpansive operators. J. Nonlinear Convex Anal. 2018, 19, 407-415.

39. Yao, Y.; Chen, R.; Xu, H.-K. Schemes for finding minimum-norm solutions of variational inequalities. Nonlinear Anal. 2010, 72, 3447-3456. [CrossRef]

40. Yao, Y.; Shahzad, N. Strong convergence of a proximal point algorithm with general errors. Optim. Lett. 2012, 6, 621-628. [CrossRef]

41. Mainge, P.-E.; Maruster, S. Convergence in norm of modified Krasnoselki-Mann iterations for fixed points of demicontractive mappings. Set-Valued Anal. 2007, 15, 67-79.

42. Goebel, K.; Kirk, W.-A. Topics in Metric Fixed Point Theory; Cambridge Studies in Advanced Mathematics; Cambridge University Press: Cambridge, UK, 1990.

43. Xu, H.-K. Iterative algorithms for nonlinear operators. J. Lond. Math. Soc. 2002, 66, 240-256. [CrossRef]

(C) 2019 by the authors. Licensee MDPI, Basel, Switzerland. This article is an open access article distributed under the terms and conditions of the Creative Commons Attribution (CC BY) license (http:/ / creativecommons.org/licenses/by/4.0/). 